\title{
LEXICAL CATEGORIES: CONCEPT MAPPING INSTRUCTION ON THE EFFECT OF NOUN IDENTIFICATION IN FOREIGN LANGUAGE TEXTS
}

\author{
José L. Gómez, Enrique Arias, \& Juan Lirio \\ University of Castilla-La Mancha at Toledo, Spain \\ E-mail: gomezr@edu.jccm.es,Enrique.AFernandez@uclm.es,Juan.Lirio@uclm.es
}

\begin{abstract}
Concept maps basic training differences were examined in noun identification from written texts, in the context of reading and writing assignments in a foreign language. Sample groups were comprised of 10-year-old Spanish primary students who attend a bilingual school. Both male and female participants were included in the non-randomized experiment. Experimental and control sample groups were accurate in identifying singular and collective nouns, including plural irregular nouns. Although the trained sample group was efficient in detecting and categorising hypernyms and first hyponyms, compared to lower hyponym categories, pupils did not precisely discriminate adjectives within the texts, sometimes confusing them with nouns. In contrast, while the non-trained sample group disclosed precision in circling nouns and discriminating adjectives within the texts, they demonstrated less precision identifying other grammatical categories. The control sample group did not reveal accuracy discriminating verbs, adverbs, and pronouns from nouns when compared to the experimental group. Because of their lack of training, the control group displayed more creativity (charts, mind maps, tree diagrams...) when asked to create concept maps, in comparison to the experimental group. However, the trained group accomplished this activity satisfactorily. The outcome of this study reveals that a three-month trained concept mapping sample group disclose achievement in discriminating specific information from English texts. These conclusions suggest that concept mapping helps students differentiate lexical and grammatical categories from written foreign texts, which will benefit them when synthesizing the information to be learned.
\end{abstract}

\section{Introduction}

Natural Science books for Spanish primary students learning curricular content in foreign languages ${ }^{1}$ (L2) are overloaded with technical information comprehending new concepts students must learn ${ }^{2}$. Teachers, by means of didactic transposition and instructional techniques, disclose the important information pupils need to be aware of. In some circumstances, teachers show students how to handle those concepts, as well as how hypernyms enclose hyponyms and how words are linked and hierarchized within texts. For that purpose, concept maps are efficient support for teachers when giving those explanations. But because of lack of time and class resources, or further reasons, it is not always feasible to teach pupils how to handle information themselves: "The extraction, selection, and prioritizing of concepts from information-dense material are often-overlooked skills vital to culling out [emphasis added] extraneous material" (Mintzes, J., Wandersee, J., \& Novak, J., 1998, p. 116). Taking this into account, the purpose of this research is to establish a first contact, from a series, with concept maps for those Spanish primary students learning curricular content in English. That is to say, studying at bilingual schools.

Considering all of the above, the objective of this study is to monitor if students trained briefly in concept map usage are able to discern specific information from English texts in a more efficient way than non-trained peers. The reason we consider discrimination of information at this age as stage-important is that it might affect present and future students' knowledge and final marks when learning curricular content in L2. The tool we propose to facilitate this is the use of concept maps. We also consider that both learning curricular content in L2 and managing concept maps demand high order thinking skills from primary students. This variable was observed in this study, causing more stress in the experimental group than in the control group because of the extra, unknown, demanding homework needed when using concept maps. For this reason, when teaching the use of concept maps to primary students, we also suggest a step-by-step concept mapping instruction from the very beginning, as well as giving pupils time to develop their skills in the use of this helpful tool. Therefore, the hypothesis inferred is that a three-month-trained experimental group will discern nouns from English texts more efficiently than non-trained students belonging to the control group. As a result, they will summarize more proficiently the information to be learned.

When acquiring knowledge in an L2, it is generally beneficial for students to summarize the curricular content managed, especially the specific information to be recalled when sitting an exam. Summarization includes using mind processes, language interpretation, and narrating (Kay, C., Roberts, J., Samuels, M., Wotherspoon, I., 2009). In summarizing content, summarists have to know how briefly to restate the essence of a text in a new and personal manner (Figure 1a \& b shows pupil's concept maps and summary ${ }^{3}$ ). In order to support learning and organise information, most CLIL (content and language integrated learning) teachers use multi-media and visual organisers

\footnotetext{
'In applied linguistics, L1 designates first language, native language, or mother tongue; L2 designates a speaker's second/foreign language.

${ }^{2}$ Yeast, sprain, taste bud, petiole, prickly, thorn, hedgehog, steppe, egret, sewage, sieve, dam, axle, fulcrum, plug, pulley...

${ }^{3}$ Ten/eleven years old participants in this study made all of the concept maps included (with permission) in this article.
} 
(Bentley, 2013). Regarding summarization, including the above mentioned culling out skills to be taught to pupils, teaching techniques to summarize are not commonly developed in the average classroom. However, research shows that summarizing facilitates learner comprehension and long-term retention of information (Wormeli, 2005). Our premise is that gradation when summarizing, from lexical categories to summaries, by means of concept mapping is significant.

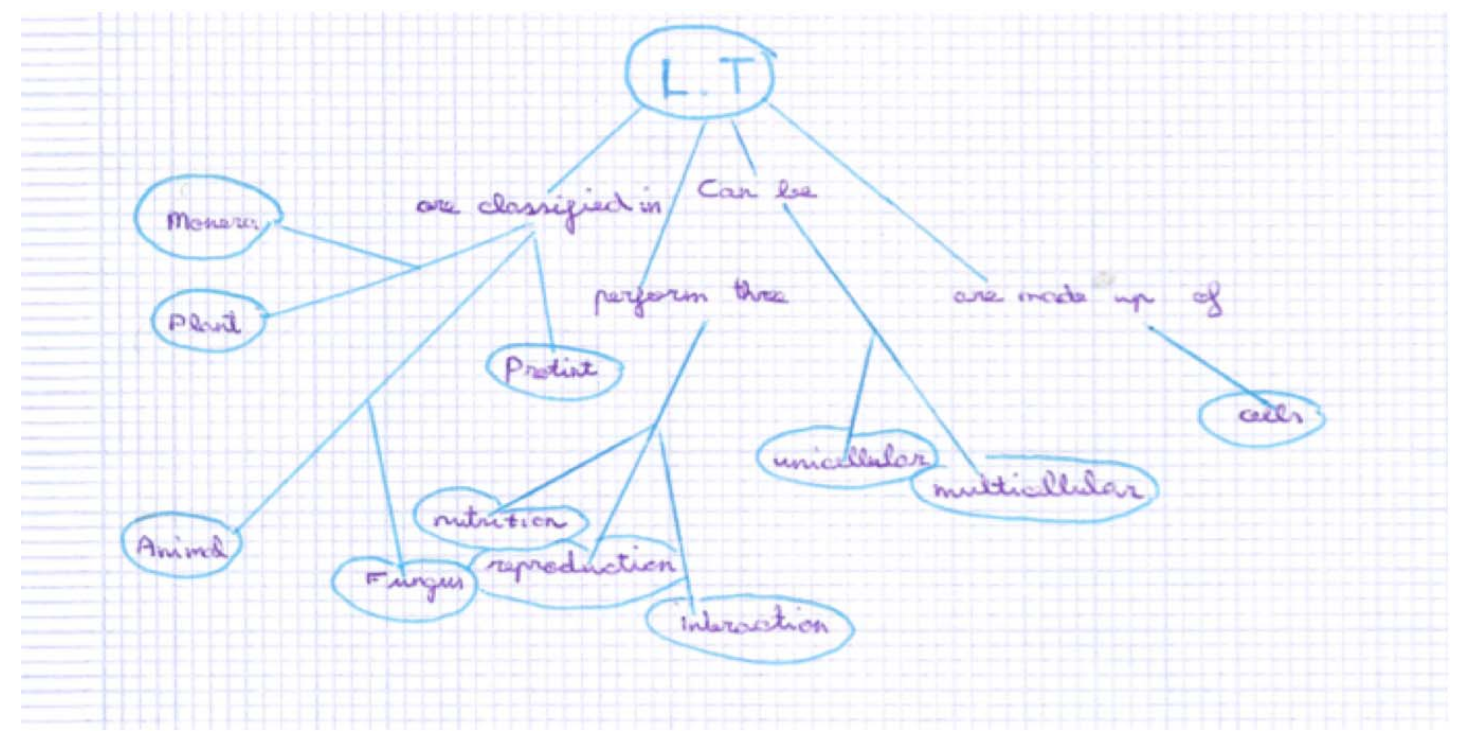

Figure 1a. Concept map made by María Santurino, a two-month-trained student.

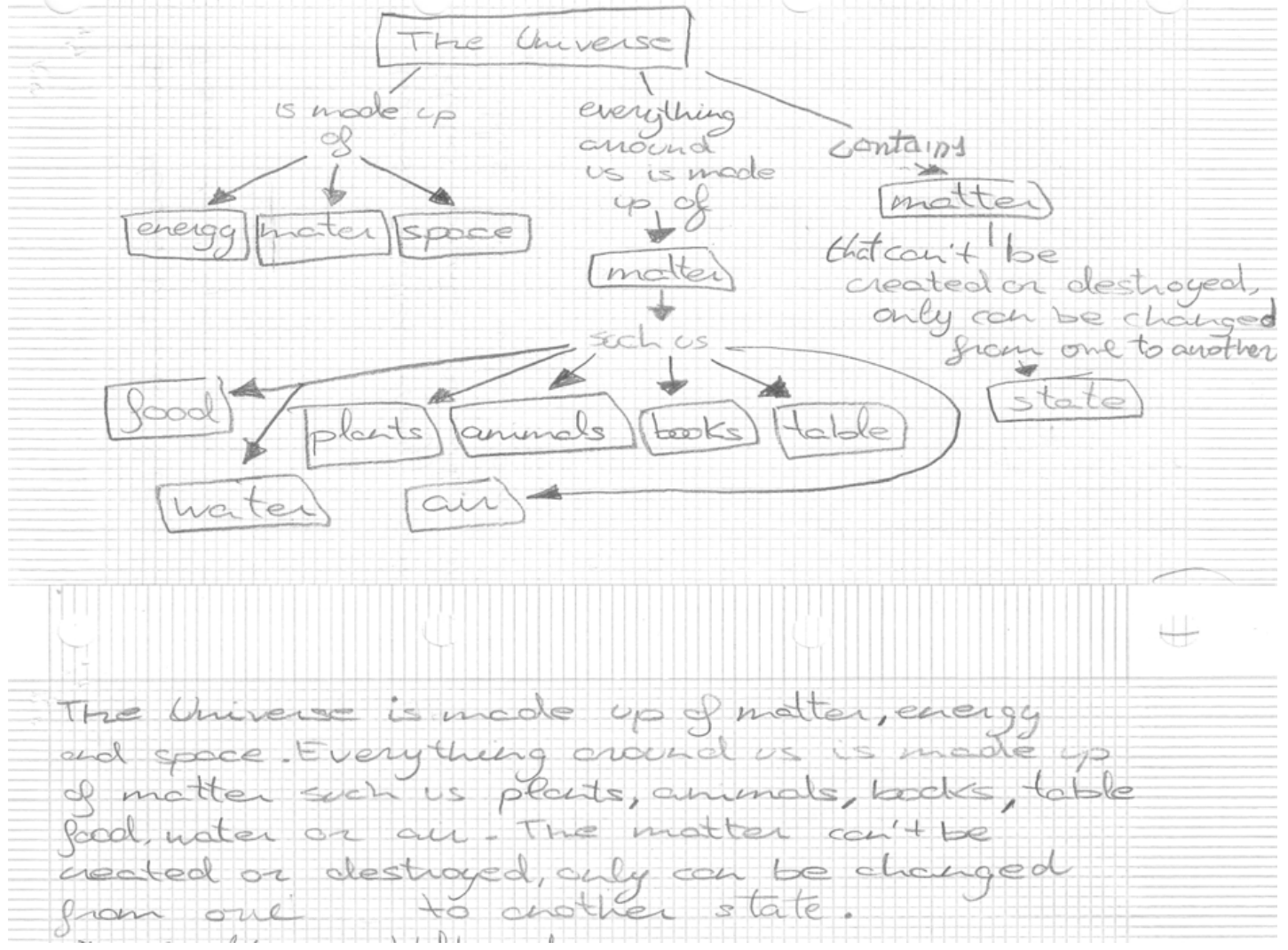

Figure 1b. Concept map and summary made by Jesús Marcos Valhondo, a six-month-trained student. 
Text comprehension in a language includes the knowledge of basic grammatical lexical categories. Furthermore, this grammar affects the way reality is perceived. Each personal view of the world is dependent on the language structure of the speaker allied to a language (Seuren, 2013). This grammatical-individual interpretation of reality implies biological matters as well, for example brain development. In some cases, both grammatical awareness and biological development represent barriers to foreigners when interpreting and summarizing curricular content in a foreign language. This occurs especially in early ages, when teachers at bilingual schools teach subjects other than English, in English, to non-native speakers. There are also external barriers for pupils to deal with, such as relatives who cannot properly help these pupils to finish their homework because they themselves are not bilingual.

Spanish primary students' misinterpretation of English texts diminishes their comprehension and long-term retention of curricular knowledge, even if they summarize the information. For that reason, the use of concept maps is highly recommended in education from early ages (Novak, 2010). To begin teaching usage of concept maps to non-English speakers, it is reasonable to initiate the instruction of pupils to the English-essential grammatical lexical categories, especially nouns. To illustrate this, in previous research where participants were requested to recall isolated words, the scores were higher for noun recognition than for verb keyword groups. An explanation for this phenomenon is as follows: "A plausible cause of this effect of grammatical class is that the referents of verbs are harder to imagine than those concrete nouns (....) more effective keywords than verbs" (de Groot, 2011, p. 97). Although in this study both groups identified most of the nouns within the four texts, they showed dissimilar results when confusing other grammatical categories as nouns. For example, the experimental group identified adjectives as nouns, whereas the control group identified verbs, pronouns, prepositions, conjunctions, and adverbs (mainly grammatical categories other than adjectives), as nouns.

To identify lexical categories, nouns within texts, pupils focus attention on two linguistic aspects: grammatical structure, and translation of words to recognize their meanings and semantic fields. Structurally, students segment texts by scrutinising the syntax to identify words according to their position within the sentence. This is not an easy task for primary pupils. They identify, underline, highlight, or extract each word categorizing the grammatical structure and word functions. Semantically, children associate words with their meanings by means of looking for their denotative significances in bilingual or monolingual dictionaries. They also request translation from peers and teachers. In some circumstances, "When children are beginning to discover written [foreign] language, helpful adults often act as mediators by saying what the printed words are, leaving to the child the more complex task of [grammatically] discovering how to distinguish one word from another" (Smith, 2004, p. 132).

As a consequence, pupils that commonly use concept maps to deal with information are supposed to effortlessly identify word categories within natural science texts. This instruction makes them aware that word functions are different. They are conscious that nouns are dissimilar to the rest of the grammatical words because they are words enclosed within boxes in the concept map frame. They understand that, when those concepts are placed in order, some words are more inclusive than others. Instructed pupils also discern that those concepts are connected to each other by means of linkers, which contain different word categories other than concepts (Novak, 1988). Undoubtedly, the more prior knowledge pupils have about the curricular content, the easier it is for them to identify nouns and other lexical categories within a text, thus easier to acquire more significant learning (Ausubel, 1968). But to learn new curricular content in a foreign language can be confusing for students whose English level is below the lexical-grammatical content in their class books, unless they have previously been trained in the use of concept maps.

A clearer example can be seen below (Figure 2a \& b), where a trained and a non-trained students in the use of concept maps were asked to do task one ${ }^{4}$ from text $D$. This consisted of making a concept map from an approximately 158 -word text, including the title and headings. Both groups performed this task at the same time and none of them, in theory, had had previous knowledge about the curricular content. While doing the task, they were not allowed to ask teachers or classmates for help, or use a dictionary. As a result, the three-month trained student in the use of concept maps appropriately encloses concepts, but still identifies some adjectives as nouns. A reasonable explanation for this could be that the headings they had been using to make concept maps from their class books (large letters and green or black bold print) were normally made up of two or more words, usually composed of an adjective and a noun (Living Things) but sometimes included other grammatical categories of words (Parts of Plants). Similarly, the non-trained student chooses nouns and adjectives as hypernyms, but chooses a different visual organizer and adds extra words in it.

\footnotetext{
${ }^{4} \mathrm{~A}$ more detailed explanation of the activities is given in 2.2 Materials and procedure.
} 


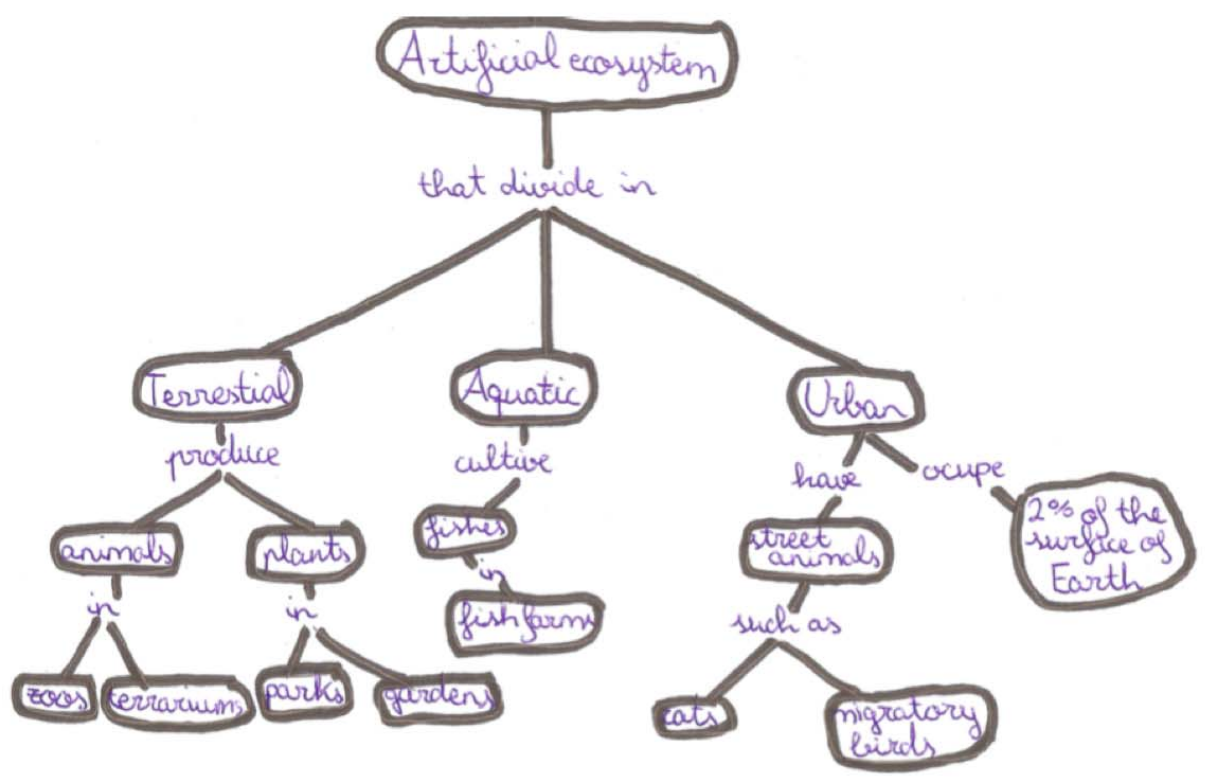

Figure 2a. Three-month-trained student's creation when asked to make a concept map from task D1 (by Mateo Jiménez).

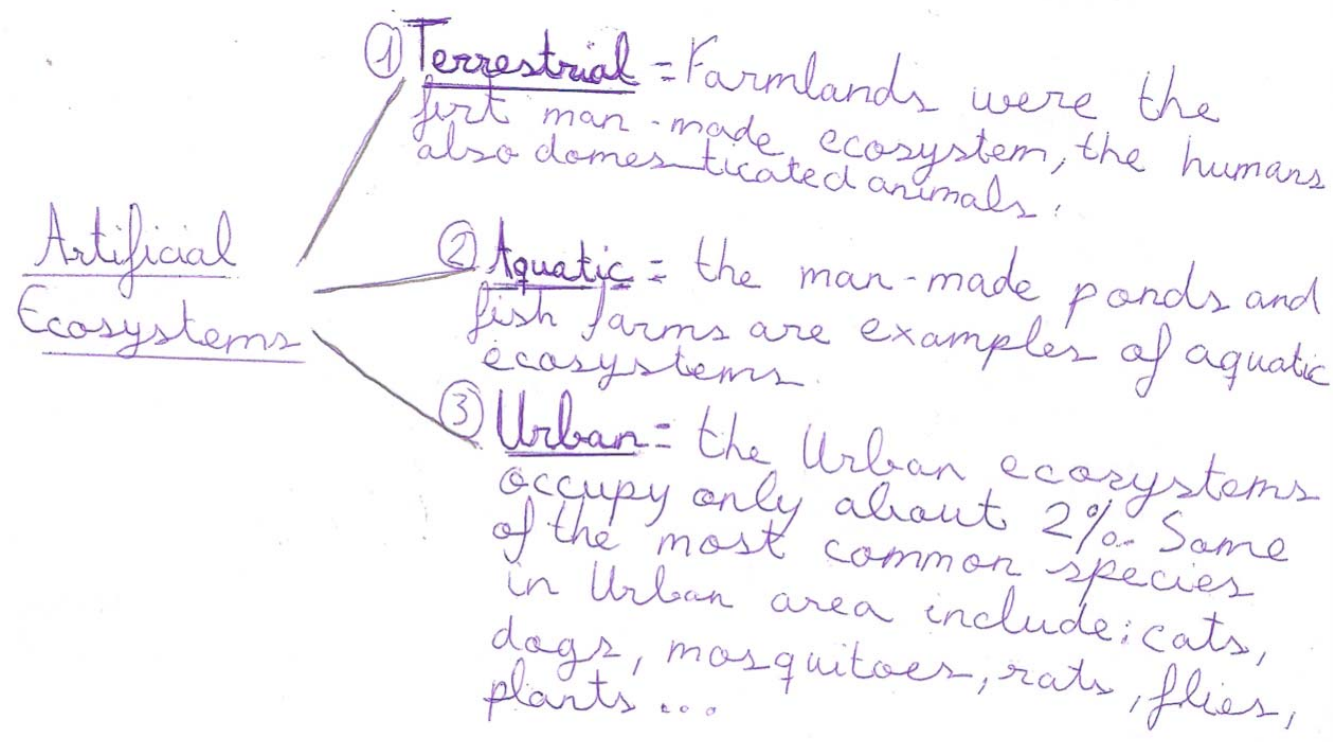

Figure 2b. Non-trained student's creation when asked to make a concept map from task D1 (by Cayetana Durán).

\section{Method}

This experiment consists of a quantitative research. By means of noun identification within written English texts, we aim to determine concept mapping trained students' comprehension and abstraction. We have designed a posttest case study in which a formative teaching has been applied to one of the analysed groups. The analysis is descriptive, to provide the analysed students' profile. This contingency analysis, or crosstabs, allows us to establish a relational level between variables. Finally, the average comparative analysis will show the difference existing between the two groups, the experimental and the control ones. 
For counting and for evaluation of the detected nouns and non-nouns, we have used three equal intervals, based on the selected nouns' rank according to each of the fulfilled activities. We have gradually named these intervals so that correct answers and errors can easily be identified.

Correct intervals are identified as follows:

- $\quad$ Excellent $=3 / 3$

- $\operatorname{Good}=2 / 3$

- $\quad$ Developing $=1 / 3$

Error intervals are identified as follows:

- $\quad$ Excellent $=3 / 3$ errors

- $\operatorname{Good}=2 / 3$ errors

- $\quad$ Developing $=1 / 3$ errors

Observe that error intervals are the opposite of correct answer interval, the fewer the errors (developing) the better the result.

\subsection{Participants}

Two equivalent groups of subjects-experimental $(\mathrm{n}=30)$ and control $(\mathrm{n}=30)$-differently treated. Sample groups consisted of fifth-grade student, all Spanish-language speakers, aging between 10-11 $(M$ age $=10.5)$, selected from a bilingual school located in Castilla-La Mancha, Spain. Experimental (male $=19$; female $=11)$ and control (male $=20$; female $=10$ ) groups were randomly assigned. Yet, individuals belonging to each group were not randomly assigned. In the table below (Figure 3) percentages of representation (males and females) belonging to each group, and collectively, can be seen. They were unmodified, naturally existing groups: two fifth grade classes. Groups did not significantly differ in any incidental characteristic. However, a special-need pupil coexisted in the experimental group during the experiment. Tasks for this participant were translated into Spanish. Another particularity is that a slightly higher subject mark average from the previous school year was observed in the control group (0.4), compared to the experimental group. $100 \%$ of the group members participated in the experiment.

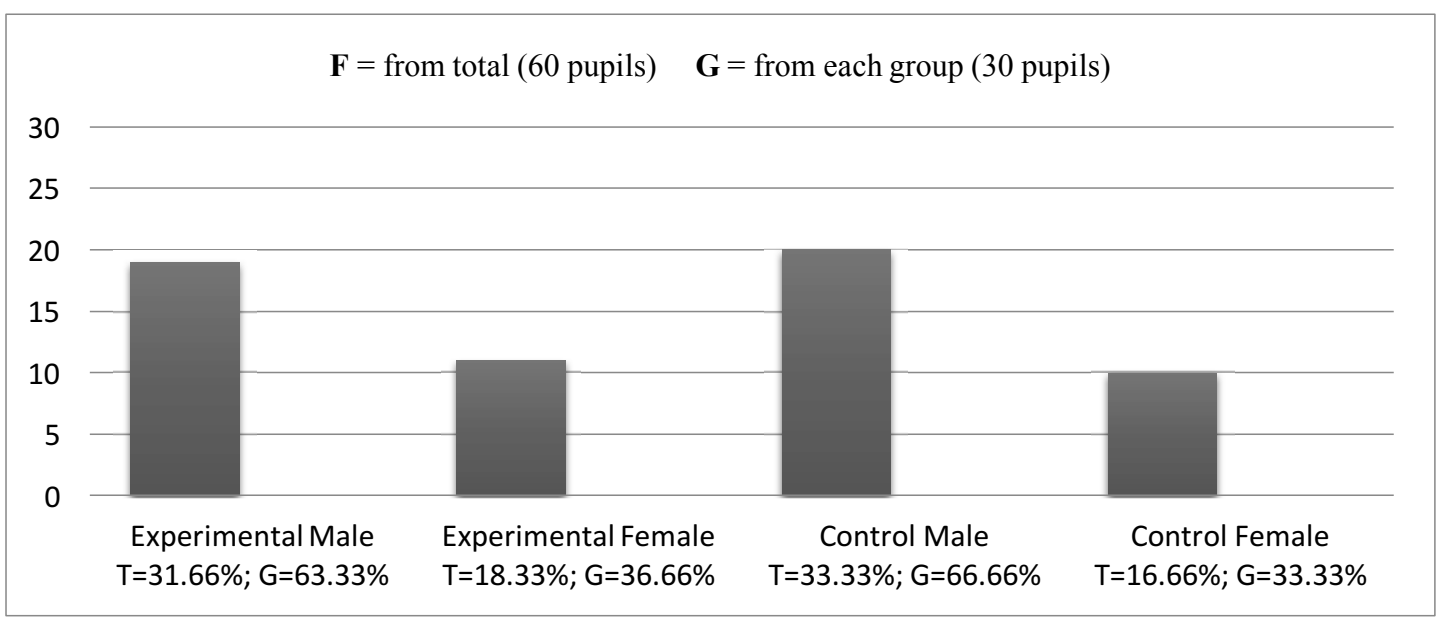

Figure 3. Experimental \& control percentage representation (male, female, per group, total and partial in both groups).

\subsection{Materials and procedure}

Four texts were adapted from the pupils' Natural Science book (Riach M. and Bacon T., 2014), whose curricular content is based on the Castilla-La Mancha 54/2014 Decree. The reason these texts were chosen from this book is because it is the textbook that both groups were using during the 2015-2016 school year. Curricular content belongs to Unit 5, "Ecosystems". This unit was being taught during the same period of time when the experiment 
took place. This encompasses pages 68 to 73 of the book ${ }^{5}$. The text format, adapted for the experiment, was the same as the textbook format, but drawings and other noun-identification facilitators were omitted. Highlighted and bold print within the task texts was also deliberately excluded. Only titles, paragraph headings, and some hypernyms appeared in bold within the task texts for reference purposes. Texts were written in English but, to facilitate students' understanding, instructions in Spanish were included (Figure 4 shows an example of task instructions).

ACTIVITY (do it in English and step by step):

1. You can use either a pen or a pencil. You can also underline, highlight, or write on the paper.

2. Write your name, date, grade, and group you belong to.

3. Answer this question: Do you attend extra particular classes other than English? YES $\square \quad$ NO

4. Make a concept map from the reading. You cannot ask for help to your teacher or classmates. You are not allowed to use a dictionary.

Figure 4. Tasks instructions were given in Spanish. The instructions above belong to task one, text D (D1).

Assignments consisted of four readings with two tasks to perform in each, 8 tasks total. Tasks 1 (4) varied from text to text (qualitative); tasks 2 (4) were common to all texts (quantitative). A total of eight tasks or steps were carried out as normal classroom activities, lasting approximately three hours total ( $T$ average $=22^{\prime} 5^{\prime \prime}$ per task). The sole purpose of the four task ones (T1) was in order for students to establish a first contact with the curricular content.

Tasks were developed as follow:

1 In the first assignment (T1), students were asked to summarize text $\mathrm{A}$ into a paragraph without text translation or explanation. Next, translation and explanation of the text took place with their teacher. Finally, completion of task two (T2), using the same text A, consisted of circling all the nouns within the reading.

2 In the second assignment, text B, students were asked to condense the text for a study purpose without text translation or explanation, as they usually do when summarizing information (T1). Next, they had to describe the process or steps they followed in order to do this task. Finally, translation and explanation of the text took place with their teacher. Then they completed task two (T2), by circling all the nouns from the reading.

3 In the third assignment, pupils were asked to extract the nouns from text $\mathrm{C}$ without any translation, explanation, or use of dictionaries (T1). Next, translation and explanation of the same text took place with their teacher. Finally, they completed task two (T2) by circling all the nouns from the same reading C.

4 In the fourth assignment, without text translation or explanation, students were asked to create a concept map of text D (T1). Next, translation and explanation of text D took place with their teacher. Finally, they completed task two (T2) by circling all the nouns from the same text D.

Assignments from texts A, B, C, D, consisted in two tasks per text. This process was always routine (tasks one [T1] consisted of pupils having a first contact with the texts, then translation into Spanish, and finally, tasks two [T2], consisting of circling all the nouns from the texts).

Regarding materials, no special resources were needed. Students were given blank sheets of paper and texts A, B, C, D with the instructions in Spanish, to fulfil each session's tasks. Four different texts were used for the four assignments (A, B, C, D), whose nouns were to be circled by the students during each session-quantitative tasks two (T2) named A2, B2, C2, and D2. The additional piece of paper was used to complete qualitative tasks one-named A1, B1, C1, and D1. Students were asked to have a pen, pencil, eraser, and coloured pencils on their desks before starting the tasks. To finish qualitative tasks, students belonging to the experimental group asked for extra blank sheets of paper to complete some of the tasks. The vast majority of components in this group had

\footnotetext{
${ }^{5}$ Because of Copyright none of these pages are included.
} 
difficulties completing the task within the space designated to do tasks B1 (condensing the text for a study purpose in the way they usually did) and D1 (making a concept map), in comparison to the control group.

\section{Results}

As shown in the next bar chart, in both selected groups male representation was higher $(65 \%$ male, $35 \%$ female from [60] total). All participants are in the same grade and are of similar age (10 to 11 years old [ $M$ age $=10.5]$ ). There is almost no difference in their extracurricular training classes, with only a slightly higher percentage for those belonging to control group, with the exception of extracurricular English classes (see Figure 5).

Percentage results referring to this aspect are as follow:

Experimental group (some students might attend both classes, English and other subjects, simultaneously)

- $33.3 \%$ of the students do not attend extracurricular classes

- $66.6 \%$ of the students attend extracurricular English classes

- $20 \%$ of the students attend extracurricular non-English subjects (maths, Spanish...)

Control group (some students might attend both classes, English and other subjects, simultaneously)

- $63.3 \%$ of the students do not attend extracurricular classes

- $36.6 \%$ of the students attend extracurricular English classes

- $23.3 \%$ of the students attend extracurricular non-English subjects (maths, Spanish...)

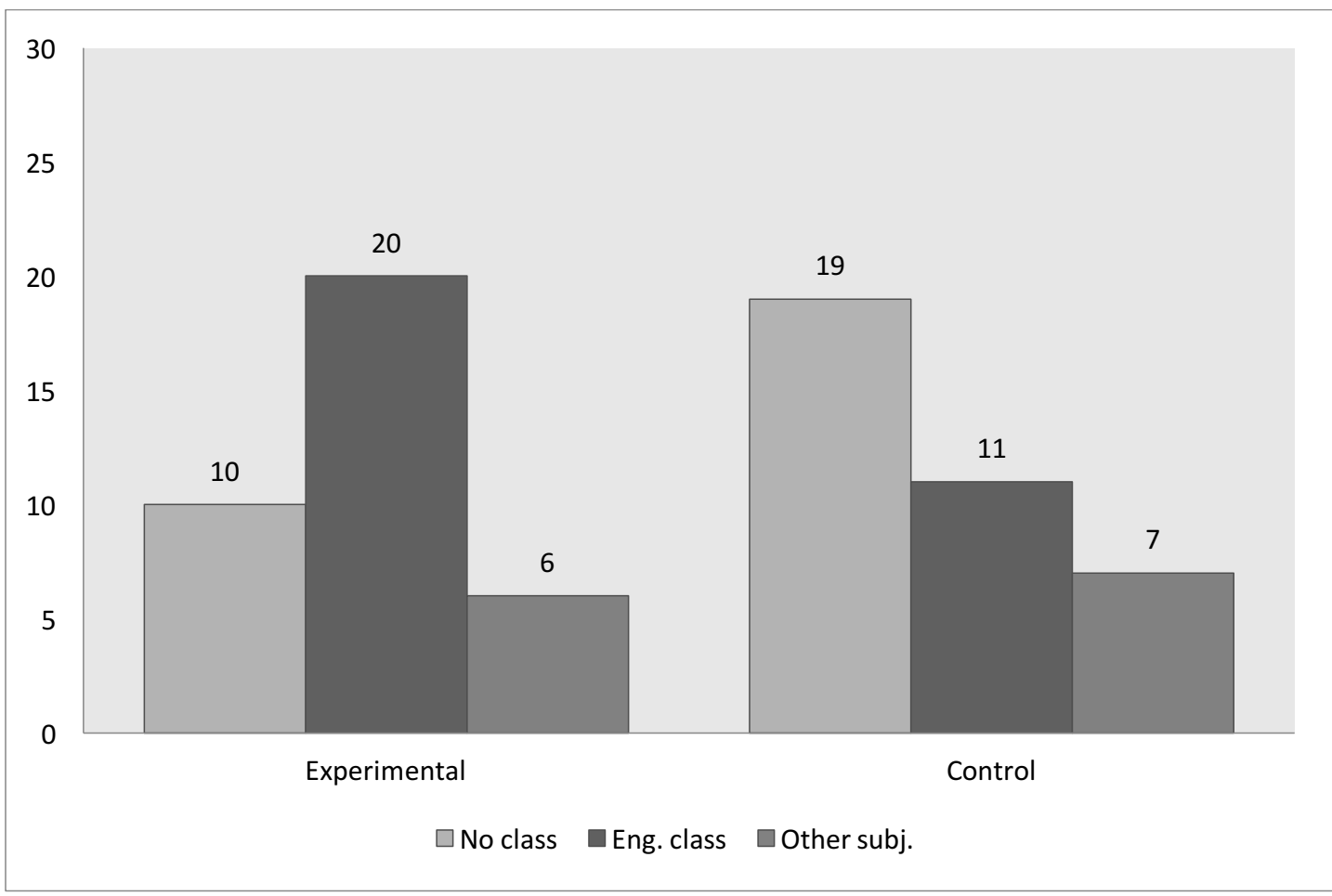

Figure 5. Students per group attending or not to private English, and other subject, classes.

Regarding the results of the four tests, the nouns correctly identified in each text show us that higher percentages are located within the superior interval entitled "excellent" (see Figure 6). Paradoxically, regarding the number of undetected nouns, and thus errors, the majority of both groups tend to be within the higher interval as well, with the exception of the A2 test where they are indeed within the lowest interval. This fact reflects the lower degree of complexity and less number of words, and thus nouns, in the A text. 


\begin{tabular}{|c|c|c|c|c|}
\hline CORRECT & Text A2 & Text B2 & Text C2 & Text D2 \\
ANSWERS IN: & $74.25 \%$ & $82.69 \%$ & $83.74 \%$ & $88.33 \%$ \\
\multirow{2}{*}{ Experimental } & $3 / 3 \mathrm{rank}$ & $3 / 3 \mathrm{rank}$ & $3 / 3 \mathrm{rank}$ & $3 / 3 \mathrm{rank}$ \\
\hline \multirow{2}{*}{ Control } & $89.16 \%$ & $85.90 \%$ & $84.33 \%$ & $90.89 \%$ \\
& $3 / 3 \mathrm{rank}$ & $3 / 3 \mathrm{rank}$ & $3 / 3 \mathrm{rank}$ & $3 / 3 \mathrm{rank}$ \\
\hline \multirow{2}{*}{ ERRORS IN: } & Text A2 & Text B2 & Text C2 & Text D2 \\
\hline \multirow{2}{*}{ Experimental } & 190 & 719 & 694 & 832 \\
& $(6.33 \%=1 / 3)$ & $(23.96 \%=3 / 3)$ & $(23.13 \%=3 / 3)$ & $(27.73 \%=3 / 3)$ \\
\hline \multirow{2}{*}{ Control } & 226 & 768 & 538 & 711 \\
& $(7.53 \%=1 / 3)$ & $(25.60 \%=3 / 3)$ & $(17.93 \%=2 / 3)$ & $(23.70 \%=3 / 3)$ \\
\hline
\end{tabular}

Figure 6. Percentages of correct answers and number of errors per group and task.

From the contingency analysis, it can be seen that no significant relationship exists between the gender variable and the correct vs. error variable when identifying nouns, with the signification indicators in the chisquare test above 0.05 . These variables in the four tests run have no significant relation to the extracurricular English class variable either, and therefore do not discriminate. The levels of signification also rise above 0.05. The same occurs with the variable group (experimental or control). There is no table with an existing significant relation, and therefore, having been trained to use concept maps during a three-month period of time does not imply having better results in noun identification in either of the texts.

Finally, in the t-test for independent samples, the results give us average results above 2.5. This indicates that noun identification would be in the highest levels in both groups (excellent). The averages of the non-identification of nouns would oscillate in the middle levels. This occurs in both groups. Analyzing the differences in the averages, we can observe that the difference is only significant in the A2 test, with a difference of -0.333 (Figure 7). Here, a distance is established between the groups, favouring the experimental group over the control one. As for the rest of the texts $(B 2, C 2, D 2)$, the differences are not significant. It could be said that there is no difference between the groups. Therefore, we are working with considerably homogenous groups in regards to the number of nouns identified.

\begin{tabular}{|l|c|c|c|c|}
\hline & \multicolumn{2}{|c|}{ Levene's test for equality of variances } & \multicolumn{2}{c|}{ Mean differences } \\
\cline { 2 - 5 } & $\mathrm{F}$ & $\mathrm{S}$ Sig. & -2.955 & -0.333 \\
\hline Correct answers in A1 & 43.817 & 0.000 & -1.680 & -0.167 \\
\hline Errors in A1 & 12.900 & 0.001 & -0.548 & -0.067 \\
\hline Correct answers in A2 & 1.225 & 0.273 & -0.851 & -0.067 \\
\hline Errors in A2 & 3.030 & 0.087 & 0.000 & 0.000 \\
\hline Correct answers in A3 & 0.000 & 1.000 & 1.166 & 0.167 \\
\hline Errors in A3 & 1.927 & 0.170 & -0.584 & -0.033 \\
\hline Correct answers in A4 & 1.396 & 0.242 & 0.808 & 0.133 \\
\hline Errors in A4 & 1.783 & 0.187 & & \\
\hline
\end{tabular}

Figure 7. Test statistics. 


\section{Discussion}

Some conclusions can be observed from the obtained results. Firstly, that we are using two almost perfectly homogenous groups in regards to their capability of identifying nouns within the texts, all of them displaying acceptable results. This alone proves true success through training/instruction of concept maps to the experimental group.

The justification is as follows:

- This group started the academic year with a difference of 0.4 average subject marks lower, compared to the control group

- Within the A, B, C, and D texts, these trained students essentially made the mistakes by circling adjectives as nouns, compared to the control group

- To make use of concept maps easier, these pupils were allowed to include within the boxes whole propositions (mainly headings formed by an adjective and a noun)

Due to these factors, the statistical figure given to us in t-test, which shows that there are hardly any differences between the two groups, implies the acquisition of comprehensive and abstraction skills by the experimental group. This means that the experimental group, which had demonstrated a lower academic level before the instruction, was able to obtain the same results as the group having a higher academic level. The results also conclude that neither the gender nor the extracurricular English classes would be variables that discriminate, regarding the number of nouns identified in the tests. Therefore, the level of comprehension is not determined by these variables, confirming that gender does not determine the levels of cognition.

At the methodological level, the discussion could arise about if the division into three intervals is adequate or if, to obtain more accurate information, it would be interesting to increase these intervals to six. Likewise, there is a doubt about whether the execution of the noun discrimination activities within the texts should be before or after text translations and conceptual explanations. Another methodological discussion emerges from whether it is appropriate, at the initial concept-mapping-training stage, to allow pupils to write headings within the concept maps boxes. We found that, at this age, it is very difficult for most of them to identify and extract concepts from a text and then categorize them in hypernyms and hyponyms, and then transcribe the information into a concept map. At the beginning of the concept mapping instruction we tried to do so but finally we decided to allow them to use paragraph headings (generally encompassing adjectives and nouns such as living things, aquatic ecosystems, artificial ecosystems, coral reefs, physical environment...). This might also have been one of the reasons why the experimental group identified adjectives as nouns. This group accommodates the information that both categories of words are the same. During the experiment none of the groups were taught grammar in the Natural Science class.

From this study, information that we consider relevant for future research has emerged. It can be observed that both groups confuse other lexical and grammatical categories as if they were nouns. On one hand, the threemonth-trained experimental group made the most mistakes in identifying adjectives as nouns. In the previous paragraph we have exposed one possible cause for this reason and, in that respect, we think that with some more training they will be quite more accurate when identifying nouns. On the other hand, the control group did not get confused when discriminating nouns from adjectives. Although, what called our attention most is that this group of control made far more serious mistakes. For example, the vast majority of the participants in this group confused, that is to say they circled, what are supposed to be easily recognizable lexical and grammatical categories (verbs, adverbs, pronouns, prepositions, conjunctions...) with nouns.

In conclusion, regarding whether L1, concept mapping has positive effects in text comprehension (Chang, K., Chen, I. \& Sung, Y., 2002). In L2, it has also been demonstrated that learners having English as a foreign language who use concept maps have achieved much better learning results that those who did not (Mahnam \& Nejadansari, 2012), which means that the use of this worthwhile tool helps students to develop, one way or another, their receptive (reading \& listening) or productive (writing \& speaking) skills (see Figure 8 [0.04]). When children are developing these skills, during the pre-school/primary education stage, teachers play an important role. For this reason, we suggest some future lines of research, especially to those infant and primary teachers whose pupils are immersed in bilingual programs. First, we think that some more longitudinal research regarding the use of concept maps, from infant education on, would be appropriate. Concept maps provide a wide variety of possibilities to do this. We also consider that including the use of concept maps in the bilingual schools will be beneficial for the vast majority of the students. Finally, we suggest that other researchers at bilingual schools replicate this experiment to the same type of fifth graders, to consider the values outside this measured range to know if the tendency within this range continues outside it when being extrapolated. 


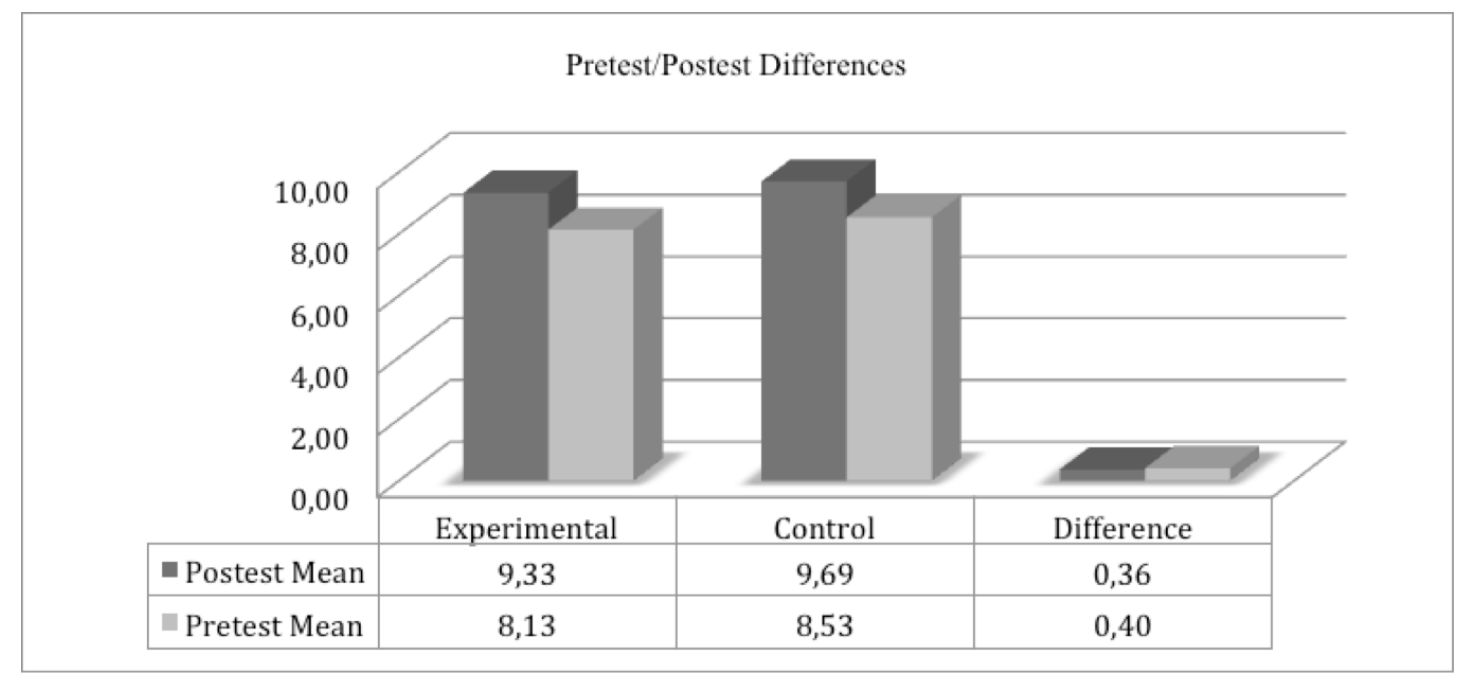

Figure 8. Graphic shows a decreasing difference between groups. Three-month-trained pupils improved their marks in 0.04 .

\section{Acknowledgements}

This research was partially supported by Santa María del Prado's school - HH. Maristas. We thank primary and high school headmasters at this school for their legal support. We also thank Yolanda and Alberto, helpful teaching staff, for their assistance during data collection.

\section{References}

Ausubel, D. P. (1968). Educational Psychology: A Cognitive View. New York, Holt, Rinehart and Winston.

Bacon, T. \& Riach, M. (2014). Natural Science: Primary 5. Zaragoza, Edelvives.

Bentley, K. (2013). The TKT Course CLIL Module. United Kingdom, Cambridge University Press.

Bussmann, H. (1998). Routledge Dictionary of Language and Linguistics. New York, Routledge.

Chang, K., Chen, I. \& Sung, Y. (2002). The effect of concept mapping to enhance text comprehension and summarization. The Journal of Experimental Education, 71 (1), 5-23.

De Groot, Annette M. B. (2011). Language and Cognition in Bilinguals and Multilinguals. New York, Psychology Press.

Kay, C., Roberts, J., Samuels, M., Wotherspoon, I. (2009). Historical Thesaurus of the Oxford English Dictionary. New York, Oxford University Press.

Mahnam, L., \& Nejadansari, D. (2012). The Effects of Different Pre-Writing Strategies on Iranian EFL Writing

Achievement. International Education Studies, 5 (1), 154-160.

Mintzes, Joel J., Wandersee, James H., \& Novak, Joseph. D. (1998). Teaching Science for Understanding: A Human Constructivist View. San Diego, Academic Press.

Novak, J. D. (1988). Conocimiento y Aprendizaje. Los mapas conceptuales como herramientas facilitadoras para escuelas y empresas. Madrid, Alianza Editorial.

Novak, J. D. (2010). Learning Creating and Using Knowledge: Concept Maps as Facilitative Tools in Schools and Corporations. Routledge, New York.

Seuren A. M., Pieter (2013). From Whorf to Montague. United Kingdom, Oxford University Press.

Smith F. (2004). Understanding Reading: A Psycholinguistic Analysis of Reading and Learning to Read. New Jersey, Lawrence Erlbaum Associates. 